\title{
Fluorescent and Colorimetric RT-LAMP as a Rapid and Specific Qualitative Method for Chronic Myeloid Leukemia Diagnosis
}

Mateus Nóbrega Aoki ( $\sim$ mateus.aoki@fiocruz.br)

Carlos Chagas Institute, Oswaldo Cruz Foundation (Fiocruz)

Anelis Maria Marin

Carlos Chagas Institute, Oswaldo Cruz Foundation (Fiocruz)

Dalila Luciola Zanette

Carlos Chagas Institute, Oswaldo Cruz Foundation (Fiocruz)

Jeanine Marie Nardin

Erasto Gaertner Hospital

Eduardo Cilião Munhoz

Erasto Gaertner Hospital

\section{Lucas Blanes}

Carlos Chagas Institute, Oswaldo Cruz Foundation (Fiocruz)

Francielle Boçon de Araújo Munhoz

Carlos Chagas Institute, Oswaldo Cruz Foundation (Fiocruz)

Bruna de Oliveira Coelho

Carlos Chagas Institute, Oswaldo Cruz Foundation (Fiocruz)

\section{Research Article}

Keywords: chronic myeloid leukemia, BCR-ABL, diagnosis, RT-LAMP, fluorescent, colorimetric

Posted Date: July 20th, 2021

DOl: https://doi.org/10.21203/rs.3.rs-712437/v1

License: (1) This work is licensed under a Creative Commons Attribution 4.0 International License.

Read Full License

Version of Record: A version of this preprint was published at Analytical Biochemistry on December 1st, 2021. See the published version at https://doi.org/10.1016/j.ab.2021.114541. 


\section{Abstract}

The detection of $B C R-A B L 1$ mRNA transcripts is essential to molecular chronic myeloid leukemia (CML) diagnosis. In most cases, the RT-qPCR technique is performed as the gold standard diagnosis tool for clinical cases. However, this method requires expensive reagents and equipment, such as a real-time thermal cycler, probes and master mix. Consequently, the development and validation of simple and lowcost methods are essential for a rapid CML diagnosis in less specialized and equipped centers. In this study, we develop and demonstrate an accessible, rapid, and low-cost method using RT-LAMP for BCR$A B L 1$ detection in both cell lines and CML clinical samples, using colorimetric and fluorescent assays. Differently to the Q-LAMP assay described in 2019 by Stella and collaborators, the samples here were analyzed by RT-qPCR and the results were compared to the results obtained by fluorescent and colorimetric RT-LAMP. The obtained data indicates that the proposed method here described is a cheaper, robust and specific approach for CML diagnosis with outstanding performance.

\section{Introduction}

Chronic myeloid leukemia ( $\mathrm{CML}$ ) is a clonal myeloproliferative disorder characterized by the translocation $\mathrm{t}(9 ; 22)$ (q34; 11 ), that generates $B C R-A B L 1$ fusion gene and protein, the hallmarks of $C M L{ }^{1}$. This agerelated neoplasm has an average diagnosis age estimated around 60 years old in western countries, however, studies indicate that in Africa and Asia the diagnostic age is about ten years younger when compared to other countries, in which the higher frequency occurs in men ${ }^{2,3}$. The American Cancer Society's estimates that in 2020 about 8,450 new cases were diagnosed in the USA with 1,130 deaths and a 5 -year survival rate of $70.4 \%{ }^{4}$. The Brazilian National Cancer Institute estimated that there were 10.810 new leukemia diagnostics in 2020, in which around 1,620 were $\mathrm{CML}^{5}$.

According to the European Society for Medical Oncology, there are standard procedures for CML diagnosis, such as the total baseline assay, differential blood cells count, bone-marrow cytology and karyotype qualitative blood RT-qPCR ${ }^{6}$. CML patients are treated with tyrosine kinase inhibitors (TKIs), one of the most effective oncological targeted therapies. This class of drugs targets the BCR-ABL1 positive cells and induce remission in most cases of CML. However, resistance and tolerance to TKIs can occur, thus, the treatment response needs to be monitored in the determined time-points in order to define the appropriate drug therapy, the effective response to the treatment and to select patients who are eligible for TKI discontinuation ${ }^{7}$.

As one of the essential components for CML diagnostics, the identification of $\mathrm{t}(9 ; 22)(\mathrm{q} 34 ; \mathrm{q} 11) B C R-A B L 1$ transcripts may be performed by qualitative molecular tests, which reduce the complexity and costs at the time of diagnosis, allowing less specialized centers to perform the tests. Real-time PCR is the goldstandard method which indicates the translocation presence, while RT-PCR technique combined with electrophoresis is performed mainly in the scientific research context ${ }^{8,9} . B C R-A B L 1$ transcripts are also 
quantified by real-time PCR to monitor the response to the TKIs treatment, demonstrating its efficiency and indicating which is the most suitable therapy drug ${ }^{10,11}$.

Recently, the Loop-Mediated Isothermal Amplification (LAMP) methodology has been studied and applied for several molecular biology diagnosis, demonstrating high sensitivity and specificity aspects ${ }^{12-16}$. This method is based on the use of the strand-displacement Bst polymerase, combined with sets of 4 to 6 primers in an isothermal procedure, usually between $60-65^{\circ} \mathrm{C}$ for $30-60$ minutes ${ }^{17,18}$. The LAMP methodology is often performed in combination to other detection techniques, such as: electrophoresis in agarose gel with ethidium bromide staining, turbidity based on the precipitation of magnesium pyrophosphate, color changes due to $\mathrm{pH}$ alteration and by fluorescence through intercalating dyes or probes ${ }^{19}$. This isothermal method can be used to detect both DNA and RNA, plus the ReverseTranscriptase enzyme can be simultaneously added to the reaction to perform a one-step RT-LAMP. Even though LAMP is manly applied for pathogens detection, it has also a promising application to the human genetic context and disease, such as screening of genetic mutations and genotyping ${ }^{20-22}$. In this study we propose a fluorescent and colorimetric RT-LAMP for detection of $B C R-A B L 1 \mathrm{~b} 2 \mathrm{a} 2$ and b3a2 isoforms in cell lines and in CML clinical samples, as a fast and specific approach in clinical practice for $\mathrm{CML}$ diagnosis.

\section{Results}

Fluorescent RT-LAMP:

First, $B C R-A B L 1$ RT-qPCR was performed using five 10-fold RNA dilutions of KCL-22 and K562 BCR-ABL1 p210 positive cell lines, ranging from $125 \mathrm{ng}$ to $0.00125 \mathrm{ng}$ per well. All RNA concentrations were detected in RT-qPCR as shown in Fig. 1. The RNA $1.25 \mathrm{ng}$ dilution presented Ct means of 29.21 and 29.11 for KCL-22 and K562, respectively, and for the 0.125 ng concentration in KCL-22 and K562, it was observed a mean Ct of 33.43 and 33.51. The RNA $0.0125 \mathrm{ng}$ dilution indicated $\mathrm{Ct}$ means of 36.41 and 38.48 , respectively. For both cell lines, the linear regression of RNA concentration returned a $r^{2}$ of 0.99 .

Using the same RNA dilution templates, three independent experiments were conducted for $B C R-A B L 1$ detection by fluorescent RT-LAMP. BCR-ABL 1 p210 transcript was detected in the assays at 125, 12,5 and $1,25 \mathrm{ng}$ per well, while the internal control was detected in all concentrations (Fig. 2). When the same experiment was performed using RNA from 10 negative $B C R-A B L$ cell lines, no amplification was detected by fluorescent RT-LAMP for $B C R-A B L 1$, while internal control was detected in all templates. Table 1 summarizes the results for KCL-22 and K562 RNA templates by RT-qPCR and fluorescent RT-LAMP for both $B C R-A B L$ p210 and internal control. 
Table 1

Summarized data for KCL-22 and K562 cell lines standard curve for $B C R-A B L \mathrm{p} 210$ and internal control. RT-qPCR mean and standard deviation Ct for BCR-ABL p210, and mean and standard deviation Tt for RTLAMP BCR-ABL p210 and internal control in 5 serial dilutions of the template

\begin{tabular}{|c|c|c|c|c|c|c|}
\hline & KCL-22 & & & K562 & & \\
\hline $\begin{array}{l}\text { RNA } \\
\text { (ng) }\end{array}$ & $\begin{array}{l}\text { RT-qPCR } \\
\text { BCR-ABL } \\
\text { p210 Ct }\end{array}$ & $\begin{array}{l}\text { Fluorescent RT- } \\
\text { LAMP BCR-ABL } \\
\text { p210 Tt }\end{array}$ & $\begin{array}{l}\text { Fluorescent } \\
\text { RT-LAMP IC } \\
\text { Tt }\end{array}$ & $\begin{array}{l}\text { RT-qPCR } \\
\text { BCR-ABL } \\
\text { p210 Ct }\end{array}$ & $\begin{array}{l}\text { Fluorescent RT- } \\
\text { LAMP BCR-ABL } \\
\text { p210 Tt }\end{array}$ & $\begin{array}{l}\text { Fluorescent } \\
\text { RT-LAMP IC } \\
\text { Tt }\end{array}$ \\
\hline 125 & $\begin{array}{l}20.6( \pm \\
0.31)\end{array}$ & $34.08( \pm 0.39)$ & $\begin{array}{l}23.35( \pm \\
1.49)\end{array}$ & $\begin{array}{l}21.01 \\
0.82)\end{array}$ & $33.21( \pm 0.60)$ & $\begin{array}{l}22.22( \pm \\
2.1)\end{array}$ \\
\hline 12.5 & $\begin{array}{l}25.25( \pm \\
0.60)\end{array}$ & $41.22( \pm 0.92)$ & $\begin{array}{l}27.93( \pm \\
2.38)\end{array}$ & $\begin{array}{l}25.19( \pm \\
0.14)\end{array}$ & $41.96( \pm 0.68)$ & $\begin{array}{l}28.17333 \\
( \pm 2.17)\end{array}$ \\
\hline 1.25 & $\begin{array}{l}29.21( \pm \\
0.08)\end{array}$ & $46.54( \pm 4.36)$ & $\begin{array}{l}32.75( \pm \\
1.94)\end{array}$ & $\begin{array}{l}29.41( \pm \\
0.02)\end{array}$ & $48.66( \pm 3.91)$ & $\begin{array}{l}32.66( \pm \\
1.60)\end{array}$ \\
\hline 0.125 & $\begin{array}{l}33.42( \pm \\
0.37)\end{array}$ & ND & $\begin{array}{l}38.83( \pm \\
0.72)\end{array}$ & $\begin{array}{l}33.5( \pm \\
0.10)\end{array}$ & ND & $\begin{array}{l}39.32( \pm \\
0.05)\end{array}$ \\
\hline 0.0125 & $\begin{array}{l}36.40( \pm \\
0.22)\end{array}$ & ND & $\begin{array}{l}46.00( \pm \\
1.32)\end{array}$ & 38.48 & ND & $\begin{array}{l}44.865( \pm \\
0.33)\end{array}$ \\
\hline
\end{tabular}

During this procedure, $39 \mathrm{CML}$ samples were evaluated by RT-qPCR for the gold-standard results. $B C R$ $A B L 1$ p210 was detected in 21 samples while the other 18 returned negative results. The internal control was detected in all analyzed samples. For $B C R-A B L 1$ p210 positive samples, the $C t$ ranged from 18.64 to 35.55, and the internal control Ct ranged from 20.3 to 28.04 (Fig. 3).

Evaluating the $39 \mathrm{CML}$ patient's data as a demographic distribution, 20 (51.3\%) were women and 19 $(48.7 \%)$ men, with a mean age of $54.60 \pm 14.88$ years old. The clinical record showed that 25 patients (64.10\%) were treated with Imatinibe, 10 (25.64\%) with Nilotinibe and 4 (10.26\%) with Dasatinibe. The treatment time indicated a significant difference $(p<0,0001)$ between $B C R-A B L 1$ p210 positive patients $(3,85 \pm 0,77$ years $)$ and negative patients $(9,12 \pm 0,91$ years), demonstrating that the treatment time is essential for BCR-ABL 1 p210 expression.

Fluorescent RT-LAMP for BCR-ABL 1 p210 detection was performed with the same $39 \mathrm{CML}$ clinical samples used in RT-qPCR. From the $21 B C R-A B L 1$ p210 positive samples assessed by RT-qPCR, 17 were also positive for fluorescent RT-LAMP, with a Tt ranging from 17.02 to 80.75 , while the IC was detected in all reactions with a Tt from 17.83 to 35.68 (Fig. 5). The 26 RT-qPCR BCR-ABL1 p210 negative samples were also negative for fluorescent RT-LAMP BCR-ABL 1 p210 reactions, with IC detection in all samples with Tt from 27.74 to 40.89 (Fig. 4). Hence, the RT-LAMP described here demonstrated $71.4 \%$ of diagnostic sensitivity and $100 \%$ of diagnostic specificity. 
Interestingly, the comparison between RT-qPCR Ct values and fluorescent RT-LAMP results revealed that all $B C R-A B L 1$ p210 positive samples with Ct lower than 28 in RT-qPCR were also positive for fluorescent RT-LAMP, demonstrating $100 \%$ of sensitivity (Table 2 ).

Table 2

Results of 21 CML BCR-ABL p210 RT-qPCR positive sample showing BCR-ABL p210 and internal control Cts and Tt for RT-LAMP for both BCR-ABL p210 and internal control

\begin{tabular}{|c|c|c|c|c|}
\hline & RT-qPCR & & RT-LAMP & \\
\hline Sample & Ct BCR-ABL & Ct IC & Tt BCR-ABL & Tt IC \\
\hline 1 & 15,52 & 21,21 & 17,02 & 17,83 \\
\hline 2 & 17,94 & 20,48 & 28,56 & 21,97 \\
\hline 3 & 19,81 & 23,96 & 24,86 & 28,81 \\
\hline 4 & 20,75 & 27,51 & 80,39 & 31,59 \\
\hline 5 & 21,5 & 24,03 & 36,68 & 30,87 \\
\hline 6 & 22,65 & 23,44 & 29,21 & 27,91 \\
\hline 7 & 23,69 & 22,52 & 39,83 & 28,93 \\
\hline 8 & 23,77 & 23,19 & 42,93 & 31,81 \\
\hline 9 & 24,08 & 23,8 & 45,47 & 26,7 \\
\hline 10 & 24,88 & 23,49 & 37,87 & 27,84 \\
\hline 11 & 25,87 & 24,02 & 30,35 & 28,92 \\
\hline 12 & 26,01 & 21,61 & 80,75 & 35,68 \\
\hline 13 & 26,4 & 22,83 & 28,04 & 30,29 \\
\hline 14 & 26,84 & 22,63 & 63,56 & 29,49 \\
\hline 15 & 28,82 & 22,83 & 49,05 & 23,48 \\
\hline 16 & 30,59 & 20,67 & 21,36 & 22,07 \\
\hline 17 & 32,45 & 22,6 & 51,46 & 26,85 \\
\hline 18 & 33,72 & 22,2 & 35,64 & 23,67 \\
\hline 19 & 34,68 & 23,26 & Undetected & 23,9 \\
\hline 20 & 34,77 & 28,04 & Undetected & 28,35 \\
\hline 21 & 35,55 & 23,77 & Undetected & 24,44 \\
\hline
\end{tabular}


Lastly, the fluorescence of RT-LAMP reactions was quantified by spectrophotometry. $B C R-A B L 1 \mathrm{p} 210$ positive and negative samples showed a significant difference in fluorescence intensity $(p<0.0001)$ and were separated into two clear distinct clusters: one with a mean fluorescence intensity of 28.527 for positive samples and another with 15.060 for negative samples. There was no difference in fluorescence intensity ( $p=0.4781)$ between BCR-ABL p210 positive and negative samples for the IC (Fig. 5).

Colorimetric RT-LAMP:

As a first result, RNA from K562 and A549 were used as template with 125, 12.5, 1.25 and 0.125ng per reaction as described, in three independent experiments. For K562 template, colorimetric RT-LAMP returned positive result (samples turning from pink to yellow) for 125 and 12.5ng/RNA while 1.25 and $0.125 \mathrm{ng}$ remained as negative (Fig. 6), while for A549 all four RNA concentrations remained negative. All internal control colorimetric RT-LAMP were positive for all samples. When both K562 and A549 colorimetric RT-LAMP were submitted to agarose gel electrophoresis we could observe that all K562 RNA concentrations were positive while no amplification was observed in A549, indicating that despite no colorimetric change in two K562 lower RNA concentration amplification occurs specifically (data not shown).

After that, we accessed $64 \mathrm{CML}$ clinical samples for colorimetric RT-LAMP using RT-qPCR as goldstandard reference. Evaluating these CML patient's data as a demographic distribution, $43.5 \%$ were women and $56.5 \%$ men, with a mean age of $59.08 \pm 13.56$ years old. The clinical record showed that $64.42 \%$ were treated with Imatinibe, $16.67 \%$ with Nilotinibe and $22.92 \%$ with Dasatinibe. In Table 3 we represent the result for RT-qPCR and colorimetric RT-LAMP for these samples, and we could observe that $66.67 \%$ of BCR-ABL p210 RT-qPCR positive samples were also positive for colorimetric RT-LAMP, while $30.56 \%$ were negative and $2.78 \%$ intermediate, where an orange color was observed. When we make a cut-off for RT-qPCR cycle threshold for samples with value above $30,90.91 \%$ are colorimetric RT-LAMP positive, $9.09 \%$ negative and $4.55 \%$ as intermediate. For RT-qPCR BCR-ABL p210 negative samples, $96.43 \%$ were negative for colorimetric RT-LAMP while $3.57 \%$ were indeterminate. All samples were positive for IC and individual data are represented at supplementary material. Figure 7a represent colorimetric RT-LAMP positive, negative and intermediate result, and $7 \mathrm{~b}$ a representative agarose gel electrophoresis for 4 positive and 4 negative samples. 
Table 3

RT-qPCR and colorimetric RT-LAMP results correlation for BCR-ABL for $\mathrm{CML}$ clinical samples, divided into RT-qPCR "overall positive", $\mathrm{Ct}<30$,

Ct $>30$ and undetected.

\begin{tabular}{|lllll|}
\hline & \multicolumn{4}{c|}{ Colorimetric RT-LAMP } \\
\hline \multirow{3}{*}{ RT-qPCR } & Positive & Negative & Intermediate \\
\cline { 2 - 5 } & Overall positive & $66.67 \%$ & $30.56 \%$ & $2.78 \%$ \\
\cline { 2 - 5 } & Ct $<30$ & $90.91 \%$ & $9.09 \%$ & $4.55 \%$ \\
\cline { 2 - 5 } Ct $>30$ & $35.71 \%$ & $64.29 \%$ & $0.00 \%$ \\
\cline { 2 - 5 } & Undetected & $0.00 \%$ & $96.43 \%$ & $3.57 \%$ \\
\hline
\end{tabular}

\section{Discussion}

Usually, CML diagnostic is conducted by clinical exams as white blood cells count and classical karyotyping. This last-mentioned method detects large genetic translocation in leukocyte DNA but represents a laborious procedure with operator-dependent efficiency, hence, it is more difficult to be performed in undeveloped countries. Molecular diagnostics are considered gold standard methods for their efficiency, cost and practical procedures when compared to conventional methodologies. The molecular detection of $B C R-A B L 1$ in $C M L$ patients not only confirms the diagnostic, but it also represents a biomarker for disease progression as well as a treatment predictor with TKIs.

Several protocols for $B C R-A B L$ detection by RT-qPCR are available in scientific literature and many international researches have performed this assay standardization ${ }^{23-29}$. The sensitivity of RT-qPCR for $B C R-A B L$ quantification assays is increasing in order to detect lower numbers of leukemia cells and minimal residual disease (MRD). However, these molecular approaches are currently expensive and inaccessible in large scale, especially for low-income countries and patients. Still, leukemia cell counts are usually high in nontreated CML patients, which indicates that these extremely sensitive and expensive tests are not necessary for diagnosis.

In the overall cancer context, screening of EGFR gene mutations at codons $746-753$ by LAMP has already been reported, in which the amplification of mutated DNA fragments were effective within 30 minutes ${ }^{30} .{ }^{31}$ developed a LAMP method to identify the EGFR mutation with a comparable efficiency to the Therascreen quantitative PCR assay, suggesting that it is a valuable alternative for the identification of oncogene mutations. In a first report by ${ }^{32}$, the authors designed an allele-specific LAMP for EGFR T790M mutation optimized with six sets of reaction mixture. According to the results, only one condition could accurately distinguish between the wild-type and the mutated DNA. A second report from the same research group demonstrated a cost effective and sensitive LAMP for detecting therapeutically-relevant EGFR hotspot mutations in a non-invasive manner. The results consistency when compared to those 
obtained by ultrasensitive droplet digital PCR (ddPCR) assay indicates the robustness of the developed method $^{33}$.

Some interesting reports emerged demonstrating the application of LAMP in the screening of mutant KRAS in oncological samples. ${ }^{34}$ developed a ligation-initiated LAMP method that in the presence of mutant KRAS DNA forms a dumbbell-shaped structure that acts as a template to initiate the following LAMP amplification. The authors detected as low as $0.1 \%$ of mutant KRAS in the presence of a large excess of wild-type KRAS DNA, plus, they successfully applied the technique for detecting a KRAS mutation in tissue samples of colorectal cancer patients. A similar result was obtained by ${ }^{35}$ where $0.1 \%$ of mutant-to-wild type KRAS ratio was detected within a lower detection limit when compared to the direct sequencing.

Stella et al. ${ }^{36}$ recently described an efficient RT-LAMP assay for BCR-ABL 1 detection, named Q-LAMP, that simultaneously detected both $B C R-A B L$ p190, p210 and internal control. In this study, 142 samples were analyzed, including newly diagnosed chronic phase CML and Philadelphia-positive ALL patients. In this study the authors reached $100 \%$ of sensitivity and specificity when compared to the results obtained by RT-PCR following the BIOMED-1 protocol ${ }^{37}$. Differently from the data here described, Q-LAMP uses RTPCR analyzed in agarose gel as gold standard, not RT-qPCR, that is a more accurate approach. This difference is important because the first method relies just in an end-point analysis with qualitative performance and does not determine the relative $B C R-A B L$ translocation quantity by returning a Ct value. The $B C R-A B L$ detection by RT-LAMP described in this study gives more details and depth regarding assay performance than the Q-LAMP reported method. Another significant difference was that the authors enrolled newly diagnosed patients, usually with a high leukemia cells count, while we accessed patients with low leukemia cells amount.

The colorimetric and fluorescent RT-LAMP described here represent qualitative assays for detecting $B C R$ $A B L 1$ most found isoforms, that performs from the reverse transcription of RNA to the isothermal amplification of $B C R-A B L 1$ in a single tube. The internal control is amplified in a separated reaction tube. Colorimetric and fluorescent RT-LAMP showed $96.43 \%$ and $100 \%$ of specificity, respectively, and concordance with RT-qPCR in paired $B C R-A B L 1$ negative clinical samples. The assay is adequate for screening diagnosis of $B C R-A B L 1$ but it does not discriminate $B C R-A B L 1$ isoforms and it is not indicated for molecular monitoring by $B C R-A B L 1$ quantification. This novel test has advantages over RT-qPCR for $\mathrm{CML}$ diagnosis because it decreases the time to obtain the results and most importantly, it reduces the costs and complexity. In conclusion, this two method variation showed a reliable and efficient approach for $B C R-A B L 1$ detection in CML patients and, in fluorescent approach can be performed not only on realtime PCR systems but also in conventional thermal cycler followed by a fluorescence spectrophotometer, allowing a broader spectrum of possibilities for its use in smaller and less specialized centers.

Colorimetric RT-LAMP is even more practical due to no need of complex equipment, just a conventional PCR system, and naked-eye result visualization, with close to $100 \%$ of diagnostic specificity and high diagnostic sensibility 


\section{Methods}

Samples: RNA from two BCR-ABL 1 p210 positive cell lines, K562 and KCL-22 (ATCC - USA) were used for the conceptual validation, analytical sensitivity and for the detection limit of fluorescent RT-LAMP. To assess analytical specificity, RNA from $10 B C R-A B L 1$ p210 negative cell lines were used: Jurkat, HL60, ReH, THP-1, Panc1, AsPC1, SW20, MiaPaCa, Capan and A549 (ATCC - USA).

The sensitivity and specificity for fluorescent and colorimetric RT-LAMP approaches were evaluated with 39 and $64 \mathrm{CML}$ clinical samples from patients in chronic phase during TKI treatment, respectively. These samples were collected in Erasto Gaertner Hospital, Curitiba, Paraná, after Erasto Gaertner Hospital Ethics Committee approval (CAAE 08809419.0.0000.0098). All samples collection and experimental conduction were carried out in accordance with guidelines and Brazilian regulations. The project was described in detail for all participants, which have read, discussed, and signed an informed consent before sample collection. For each patient, $4 \mathrm{~mL}$ of peripheral blood was collected in EDTA tubes and processed in less than 24 hours. The blood was centrifuged $\left(500 \mathrm{~g} / 10\right.$ minutes $\left./ 4^{\circ} \mathrm{C}\right)$, and the buffy coat was collected by a pasteur pipet in a $15 \mathrm{~mL}$ tube. The RNA extraction was processed utilizing a Qiamp RNA Blood Mini Kit (Qiagen) following the manual instructions. Personal and clinical data such as age, gender, diagnostic date, and treatment were also assessed from patients' charts.

Real-time PCR: To detect $B C R-A B L 1$ p210 in cell lines and clinical samples, RT-qPCR was performed using specific primers and a probe labeled with HEX for b3a2 and b2a2 BCR-ABL 1 p210 isoform. For the internal control (IC), specific primers and a probe were labeled with FAM. Reactions were conducted using GoTaq ${ }^{\circledR}$ Probe 1-step RT-qPCR Systems (Promega), with $2.4 \mu \mathrm{L}$ of oligonucleotides and $5 \mu \mathrm{L}$ of RNA, for a final reaction volume of $20 \mu \mathrm{L}$. The experiments were executed in a LightCycler96 equipment (Roche) at $45^{\circ} \mathrm{C}$ for 30 minutes, $95^{\circ} \mathrm{C}$ for 2 minutes, and 45 cycles of $95^{\circ} \mathrm{C}$ for 15 seconds and $60^{\circ} \mathrm{C}$ for 30 seconds.

Oligonucleotides and RT-LAMP conditions: For RT-LAMP assays, primers for BCR-ABL 1 p210 and 18S as internal control were designed with LAMP Designer software and used at the following concentration: FIP (Forward Inner Primer) and BIP (Backward Inner Primer) $1.6 \mu \mathrm{M}$ each; FOP (Forward Outer Primer) and BOP (Backward Outer Primer) at $0.2 \mu \mathrm{M}$ each; FL and BL (Forward Loop and Backward Loop) at $0.4 \mu \mathrm{M}$ each. The $B C R-A B L 1$ primer set was designed to detect both $\mathrm{b} 3 \mathrm{a} 2$ and b2a2 $B C R-A B L 1 \mathrm{p} 210$ isoforms. The primers were purchased from Exxtend (São Paulo, Brazil), purified by desalting, resuspended in nuclease-free water (ThermoFisher), measured by spectrophotometry in a quartz cuvette (GeneQuant Pro - Amersham Biosciences) and adjusted to $10 \mu \mathrm{M}$. Fluorescent RT-LAMP was performed in a 96 well plate with $2.5 \mu \mathrm{L}$ of $10 x$ Isothermal Amplification Buffer, $1 \mu \mathrm{L} \mathrm{MgSO}{ }_{4} 100 \mathrm{mM}, 3.5 \mu \mathrm{L}$ of dNTP $10 \mathrm{mM}, 1.25 \mu \mathrm{L}$ of EvaGreen 20x (Biotium), 1.5 $\mu \mathrm{L}$ of Bst2.0 WarmStart (NEB), $0.5 \mu \mathrm{L}$ of SuperScriptlll 200U/ $\mu \mathrm{L}$ (ThermoFisher), $10.65 \mu \mathrm{L}$ of nuclease-free water and $3 \mu \mathrm{L}$ of RNA. Reactions were performed at a LightCycler96 equipment (Roche) for 50 minutes at $64^{\circ} \mathrm{C}$ with fluorescence detection every 30 seconds. All results are represented as $T_{t}$ (Threshold time), in which unitary values correspond to 30 seconds of reaction. Each sample was subjected to separate reactions for $B C R-A B L 1$ and internal control. For colorimetric RT-LAMP reactions were performed with WarmStart® Colorimetric LAMP 2X Master Mix 
(NEB, England), in a volume of $25 \mu \mathrm{L}$ with primers concentrations as described and $5 \mu \mathrm{L}$ of RNA sample. For sensitivity improvement $1 \mu \mathrm{L}$ of Bst3.0 DNA Polymerase 8.000U/mL (NEB, England) was used. For internal control reactions were carried out in $15 \mu \mathrm{L}$ reaction using WarmStart ${ }^{\circledR}$ Colorimetric LAMP $2 X$ Master Mix (NEB, England) with primers concentrations as described and $3 \mu \mathrm{L}$ of RNA sample. The reactions were incubated at $65^{\circ} \mathrm{C}$ for 30 minutes using the ProFlex PCR System (Applied Biosystems, United States) and immediately after finishing the reaction the vials were incubated on ice. For clinical samples performed for both BCR-ABL and internal control, two separate tubes were used for colorimetric RT-LAMP. All colorimetric RT-LAMP reactions were submitted to $2 \%$ agarose gel electrophoresis (100 Volts) for 45 minutes, stained with ethidium bromide and visualized using an UV transilluminator (L-Pix Chemi, Loccus, Brazil).

Fluorescence quantification: After the RT-LAMP reaction, fluorescence quantification was measured in a spectrophotometer (Synergy H1 - BioTek ${ }^{\circledR}$ ) with $20 \mu \mathrm{L}$ of each sample using a 384-well plate at 428 and $528 \mathrm{~nm}$. Fluorescence quantification was statistically analyzed between groups with t-test by Prism GraphPad with a significant difference of $p<0.05$.

\section{Declarations}

\section{Acknowledgement}

MNA would like to acknowledge Fiocruz and Fundação para o Desenvolvimento Científico e Tecnológico em Saúde (FIOTEC) for the grant VPPIS-004-FIO-18-58.

\section{Author contribution}

MNA, AMM, DLZ planned and analyzed the experiments, and also wrote the manuscript;

JMN and ECM were enroled with ethics procedure and provided CML clinical samples together with clinical and epidemiological data;

AMM, LB, FBAM and BOC conducted the experiments, and also wrote the manuscript

All authors reviewed and approved the manuscript.

\section{Competing interests}

The author(s) declare no competing interests.

\section{Data availability}

The datasets and raw data generated during and/or analyzed during the current study are available from the corresponding author on reasonable request.

\section{References}


1. Mughal, T. I. et al. Chronic myeloid leukemia: reminiscences and dreams. Haematol. (2016) 101, 541-558.

2. Mendizabal, A. M., Younes, N. \& Levine, P. H. Geographic and income variations in age at diagnosis and incidence of chronic myeloid leukemia. Int. J. Hematol. (2016) 103, 70-78.

3. Hehlmann, R., Hochhaus, A. \& Baccarani, M. Chronic myeloid leukaemia. Lancet (2007) 370, 342350.

4. American Cancer Society, Key Statistics for Chronic Myeloid Leukemia; https://www.cancer.org/cancer/chronic-myeloid-leukemia/about/statistics.html; accessed January 11 th, 2021

5. Instituto Nacional do Câncer; www.inca.gov.br; accessed January 11th, 2021

6. Hochhaus, A. et al. Chronic myeloid leukaemia: ESMO Clinical Practice Guidelines for diagnosis, treatment and follow-up. Ann. Oncol. (2017) 28, iv41-iv51.

7. Cumbo, C., Anelli, L., Specchia, G. \& Albano, F. Monitoring of Minimal Residual Disease (MRD) in Chronic Myeloid Leukemia: Recent Advances. Cancer Manag. Res. (2020) Volume 12, 3175-3189.

8. Latham, S. et al. BCR-ABL1 expression, RT-qPCR and treatment decisions in chronic myeloid leukaemia. J. Clin. Pathol. (2016) 69, 817-821.

9. Spiess, B. et al. Diagnostic performance of the molecular BCR-ABL1 monitoring system may impact on inclusion of CML patients in stopping trials. PLoS One (2019) 14, e0214305.

10. Jovanovski, A. et al. Standardization of BCR-ABL1 p210 Monitoring: From Nested to Digital PCR. Cancers (Basel). (2020) 12, 3287.

11. Arora, R. \& Press, R. D. Measurement of BCR-ABL1 transcripts on the International Scale in the United States: current status and best practices. Leuk. Lymphoma (2017) 58, 8-16.

12. Bakre, A. A., Jones, L. P., Bennett, H. K., Bobbitt, D. E. \& Tripp, R. A. Detection of swine influenza virus in nasal specimens by reverse transcription-loop-mediated isothermal amplification (RT-LAMP). J. Virol. Methods (2021) 288, 114015.

13. Kaku, T. et al. Accuracy of LAMP-TB Method for Diagnosing Tuberculosis in Haiti. Jpn. J. Infect. Dis. (2016) 69, 488-492.

14. Fan, S.-J. et al. A pooled analysis of the LAMP assay for the detection of Neisseria meningitidis. BMC Infect. Dis. (2020) 20, 525.

15. Mohon, A. N. et al. Optimization and clinical validation of dual-target RT-LAMP for SARS-CoV-2. J. Virol. Methods (2020) 286, 113972.

16. Pham, T. H. et al. Performance of the TB-LAMP diagnostic assay in reference laboratories: Results from a multicentre study. Int. J. Infect. Dis. (2018) 68, 44-49.

17. Silva, S. J. R. da, Pardee, K. \& Pena, L. Loop-Mediated Isothermal Amplification (LAMP) for the Diagnosis of Zika Virus: A Review. Viruses (2019) 12, 19.

18. Wong, Y.-P., Othman, S., Lau, Y.-L., Radu, S. \& Chee, H.-Y. Loop-mediated isothermal amplification (LAMP): a versatile technique for detection of micro-organisms. J. Appl. Microbiol. (2018) 124, 626- 
643.

19. Shirato, K. Detecting amplicons of loop-mediated isothermal amplification. Microbiol. Immunol. (2019) 63, 407-412.

20. Ding, S. et al. One-step colorimetric genotyping of single nucleotide polymorphism using probeenhanced loop-mediated isothermal amplification (PE-LAMP). Theranostics (2019) 9, 3723-3731.

21. Gill, P. \& Amree, A. H. AS-LAMP: A New and Alternative Method for Genotyping. Avicenna J Med Biotechnol (2020) 12, 2-8.

22. Srividya, A., Maiti, B., Chakraborty, A. \& Chakraborty, G. Loop Mediated Isothermal Amplification: A Promising Tool for Screening Genetic Mutations. Mol. Diagn. Ther. (2019) 23, 723-733.

23. Tong, Y. Q. et al. New rapid method to detect BCR-ABL fusion genes with multiplex RT-qPCR in onetube at a time. Leuk. Res. (2018) 69, 47-53.

24. Kottwitz, D. et al. Evaluation of a novel multiplex RT-qPCR assay for the quantification of leukemiaassociated BCR-ABL1 translocation. Int. J. Hematol. (2015) 102, 335-341.

25. Scott, S. et al. Measurement of BCR-ABL1 by RT-qPCR in chronic myeloid leukaemia: findings from an International EQA Programme. Br. J. Haematol. (2017) 177, 414-422.

26. Serpa, M. et al. Molecular measurement of BCR-ABL transcript variations in chronic myeloid leukemia patients in cytogenetic remission. BMC Blood Disord. (2010) 10, 7.

27. Gerrard, G. et al. Fast-mode duplex qPCR for BCR-ABL1 molecular monitoring: Innovation, automation, and harmonization. Am. J. Hematol. (2012) 87, 717-720.

28. White, H. E. et al. Establishment and validation of analytical reference panels for the standardization of quantitative BCR-ABL1 measurements on the international scale. Clin. Chem. (2013) 59, 938-948.

29. Foskett, P., Gerrard, G. \& Foroni, L. Real-time quantification assay to monitor BCR-ABL1 transcripts in chronic myeloid leukemia. in Methods in Molecular Biology (2014) 1160, 115-124.

30. Komiyama, N. M. A. K. T. A. K. Detection of EGFR Gene Mutation by Mutation-oriented LAMP Method. Anticancer Res. (2018) 38(4), 2093-2099.

31. Horiuchi, S. et al. A novel loop-mediated isothermal amplification method for efficient and robust detection of EGFR mutations. Int. J. Oncol. (2020) doi:10.3892/ijo.2020.4961; 743-749.

32. Arjuna, S., Chakraborty, G., Venkataram, R., Dechamma, P. \& Chakraborty, A. Detection of epidermal growth factor receptor T790M mutation by allele-specific loop mediated isothermal amplification. J. Carcinog. (2020) 19, 3.

33. Arjuna, S. et al. Non-invasive detection of EGFR mutations by cell-free loop-mediated isothermal amplification (CF-LAMP). Sci. Rep. (2020) 10, 17559.

34. Fu, Y. et al. Detection of KRAS mutation via ligation-initiated LAMP reaction. Sci. Rep. $(2019) 9,5955$.

35. Itonaga, M. et al. Novel Methodology for Rapid Detection of KRAS Mutation Using PNA-LNA Mediated Loop-Mediated Isothermal Amplification. PLoS One (2016) 11, e0151654.

36. Stella, S. et al. The Q-LAMP Method Represents a Valid and Rapid Alternative for the Detection of the BCR-ABL1 Rearrangement in Philadelphia-Positive Leukemias. Int. J. Mol. Sci. (2019) 20, 6106. 
37. van Dongen, J. et al. Standardized RT-PCR analysis of fusion gene transcripts from chromosome aberrations in acute leukemia for detection of minimal residual disease. Leukemia (1999) 13, 19011928.

\section{Figures}

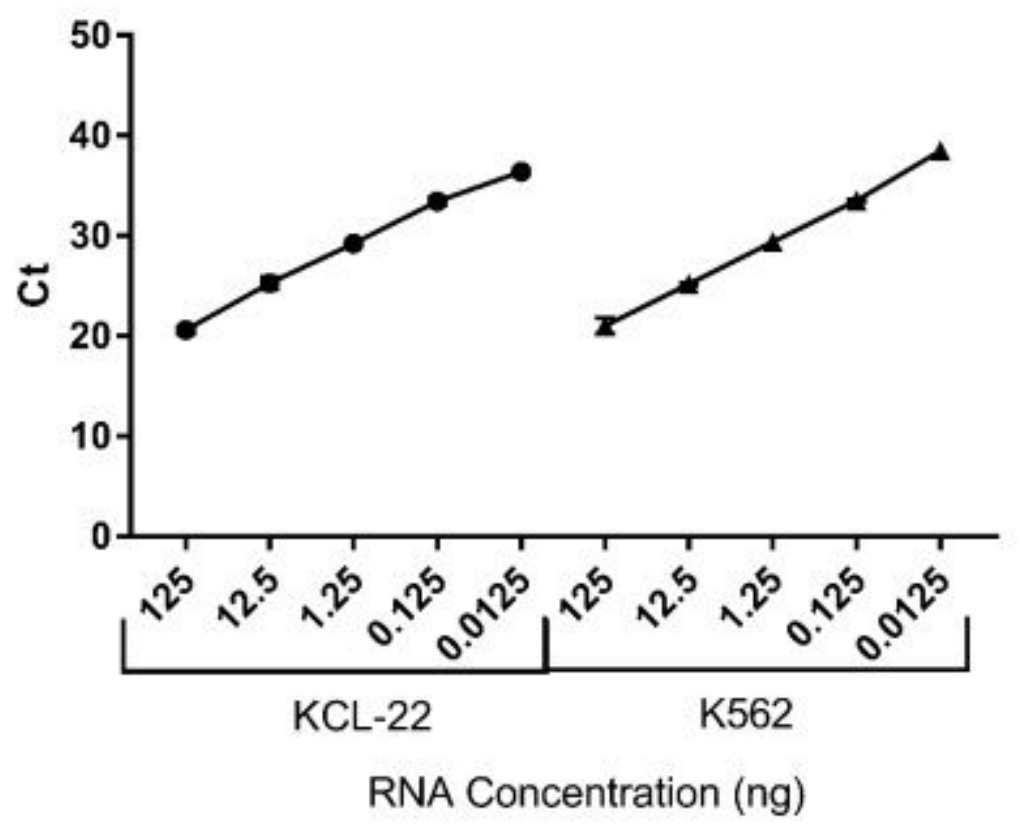

Figure 1

RT-qPCR cycle threshold for five 10-fold RNA dilutions of KCL-22 and K562 BCR-ABL1 p210 positive cell lines. All RNA concentrations were detected and returned a r2 of 0.99 for both cell lines.
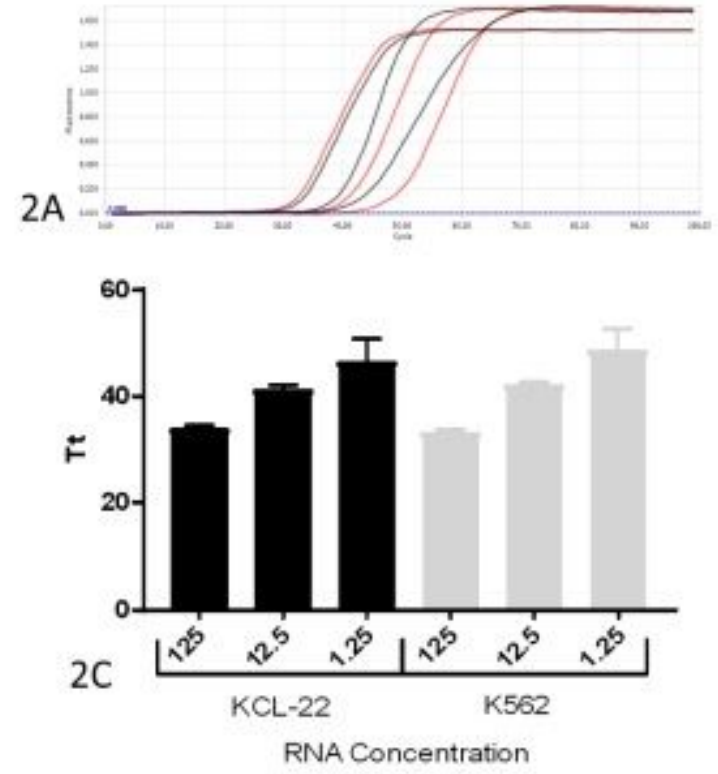
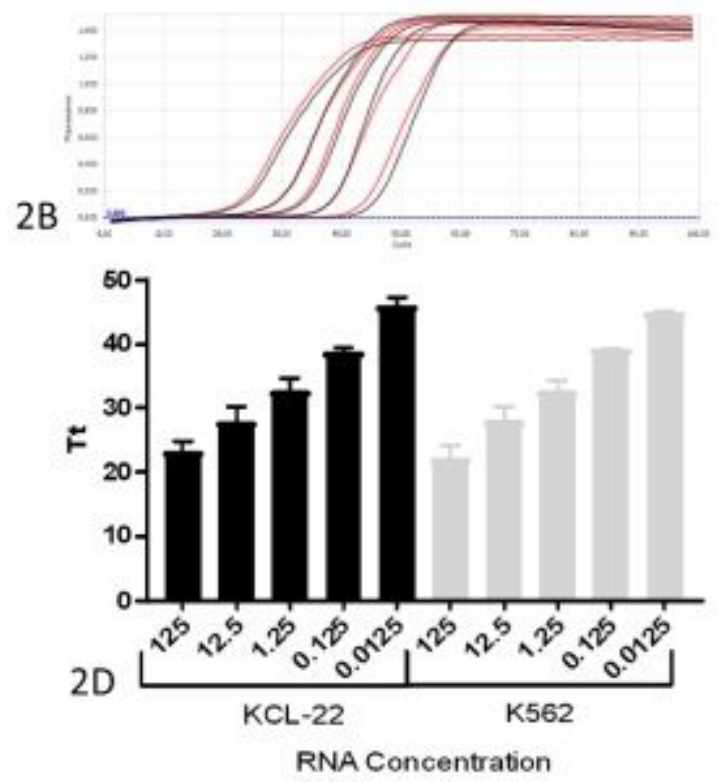

Figure 2 
A: Fluorescent RT-LAMP amplification plot for BCR-ABL p210 (left panel) with the detection of 125, 12.5 and 1.25ng of KCL-22 and K562 RNA (red and black lines, respectively) and IC (right panel) with detection in all RNA concentrations. B: Threshold time detection by fluorescent RT-LAMP with KCL-22 and K562 RNA for BCR-ABL p210 (left panel) and IC (right panel).

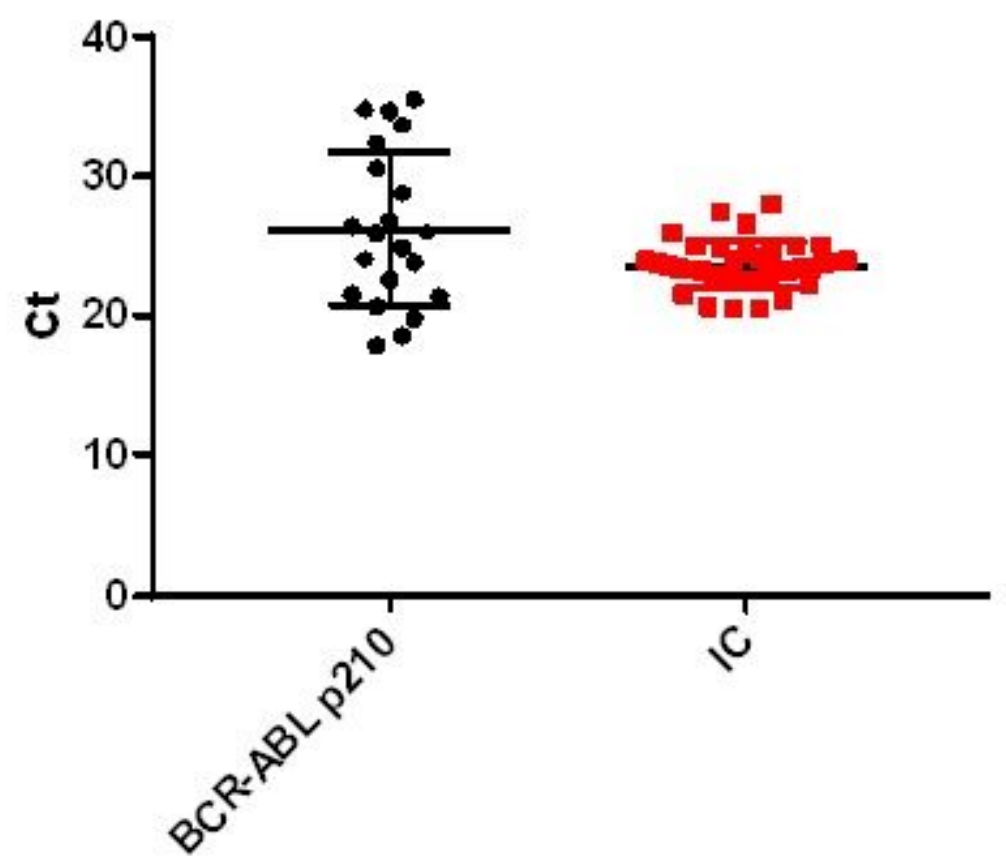

Figure 3

RT-qPCR results for BCR-ABL p210 and internal control (IC) of CML patients. BCR-ABL p210 was detected in 21 samples with $\mathrm{Ct}$ from 18.64 to 35.55 . Internal control (IC) was detected in all 39 samples, with $\mathrm{Ct}$ from 20.3 to 28.04 . 

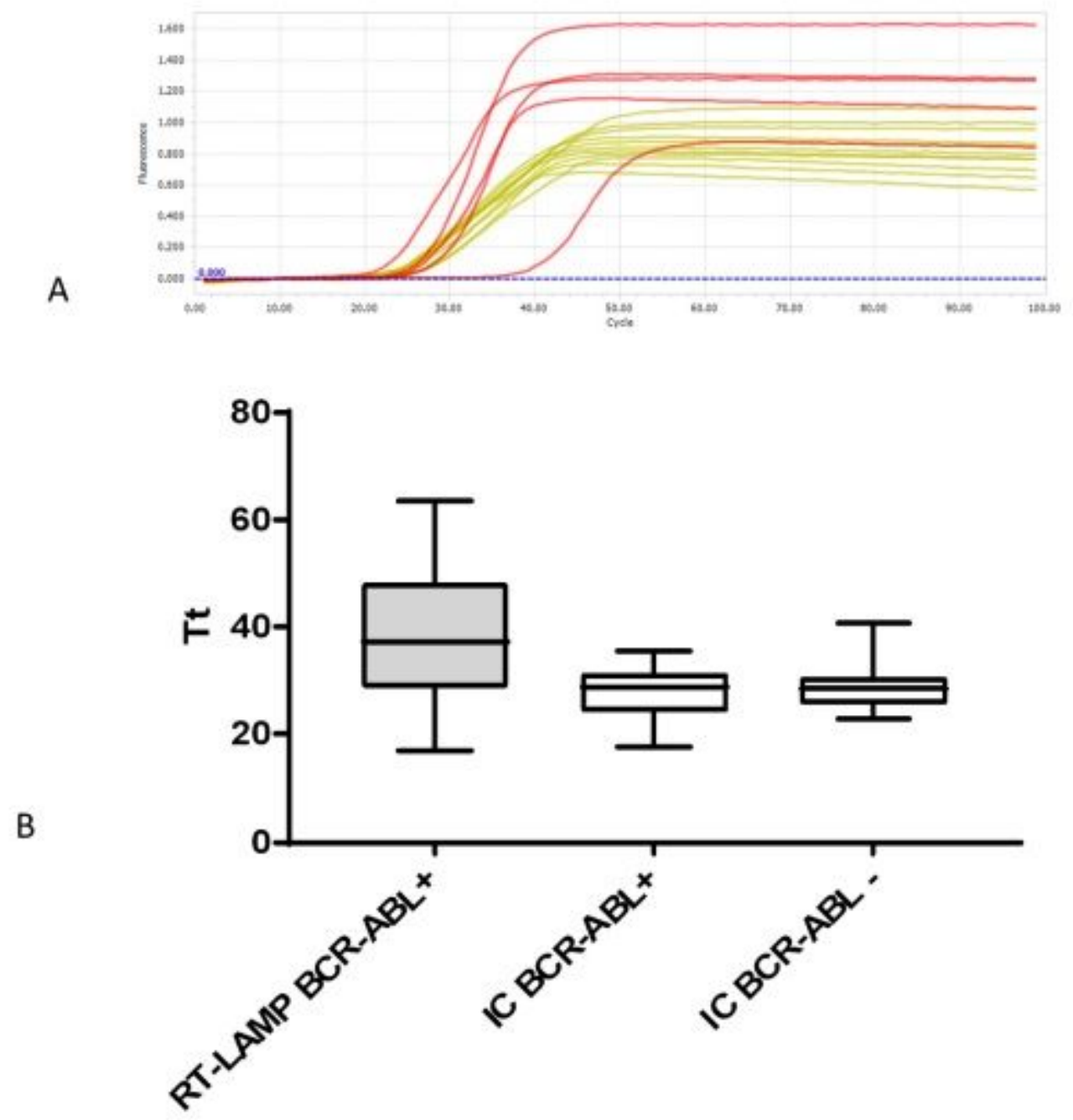

Figure 4

A: Fluorescent RT-LAMP amplification plot, representing CML BCR-ABL p210 positive samples in red and IC reactions for all samples in yellow. B: Threshold time $(T t)$ for BCR-ABL $p 210$ positive fluorescent RTLAMP and their IC, and Tt for IC of BCR-ABL p210 negative samples. 


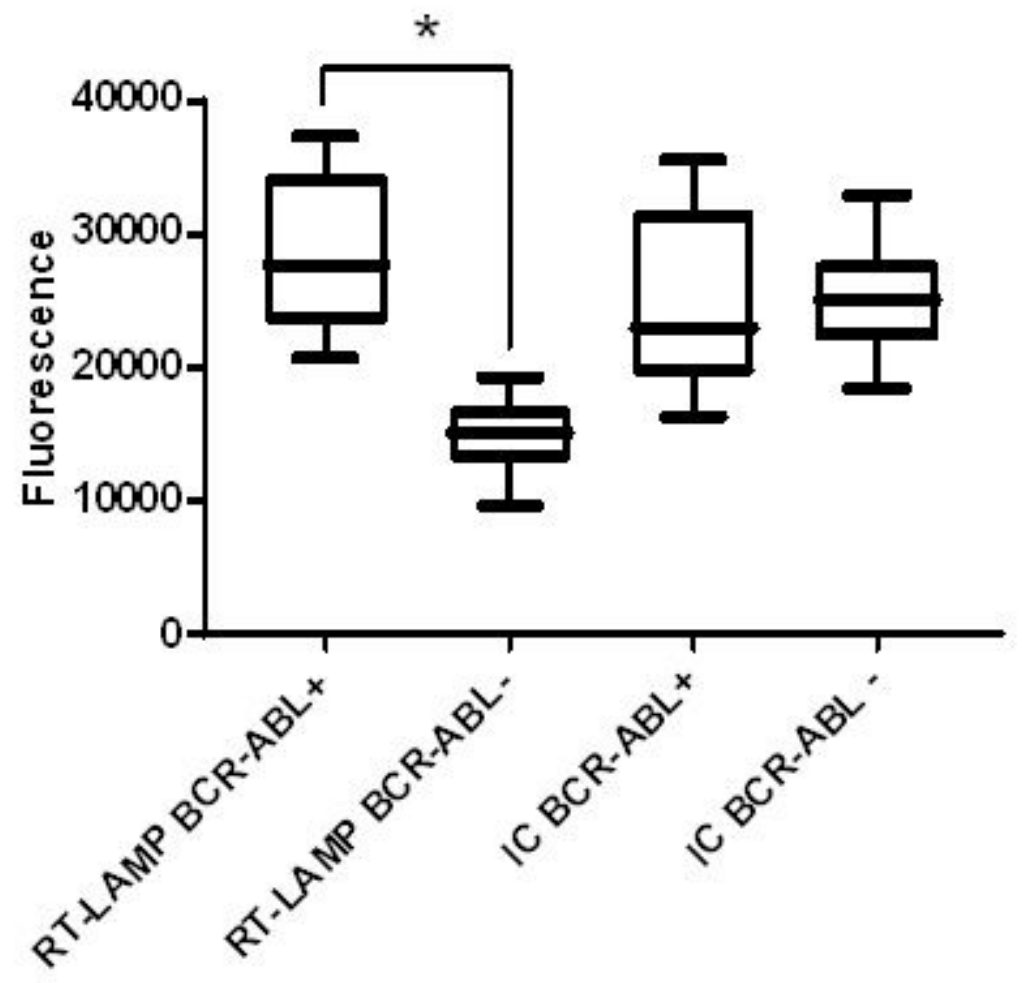

Figure 5

Fluorescence quantification of RT-LAMP reactions in spectrophotometer. A significant difference $(p<0.0001)$ in fluorescence was observed between RT-LAMP BCR-ABL p210 positive and negative samples, while no difference was observed in internal control fluorescence

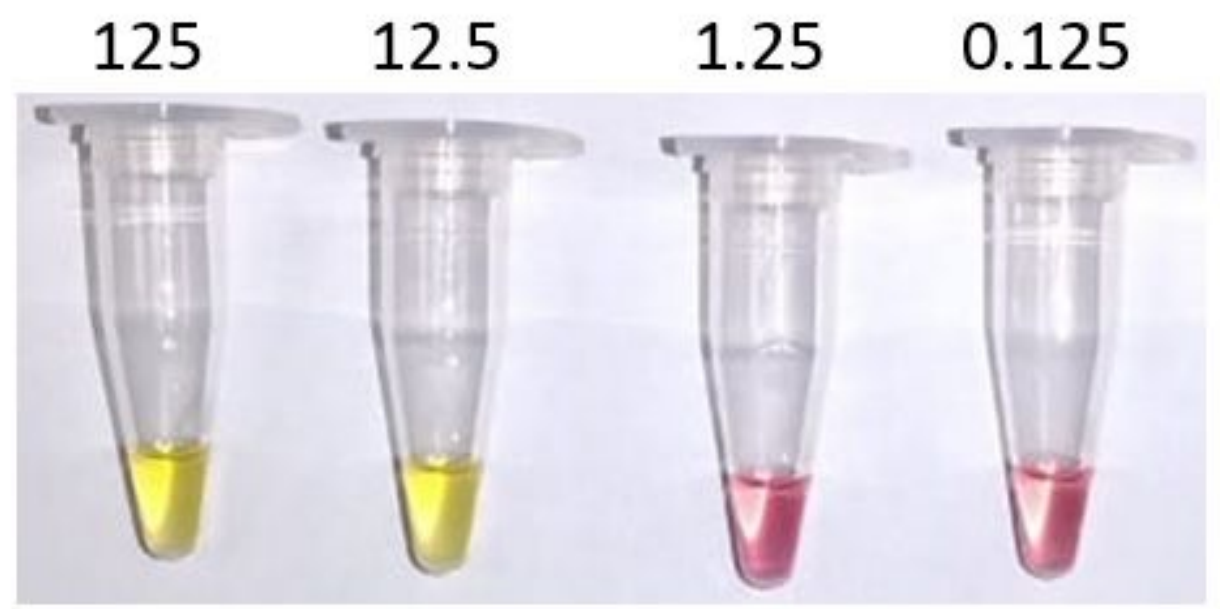

Figure 6

Colorimetric RT-LAMP for K562 RNA with $125,12.5,1.25$ and $0.125 \mathrm{ng}$ of RNA, demonstrating that two higher concentration turn yellow, indicating positive reaction, while 1.25 and $0.125 \mathrm{ng}$ remain red as negative reaction. 


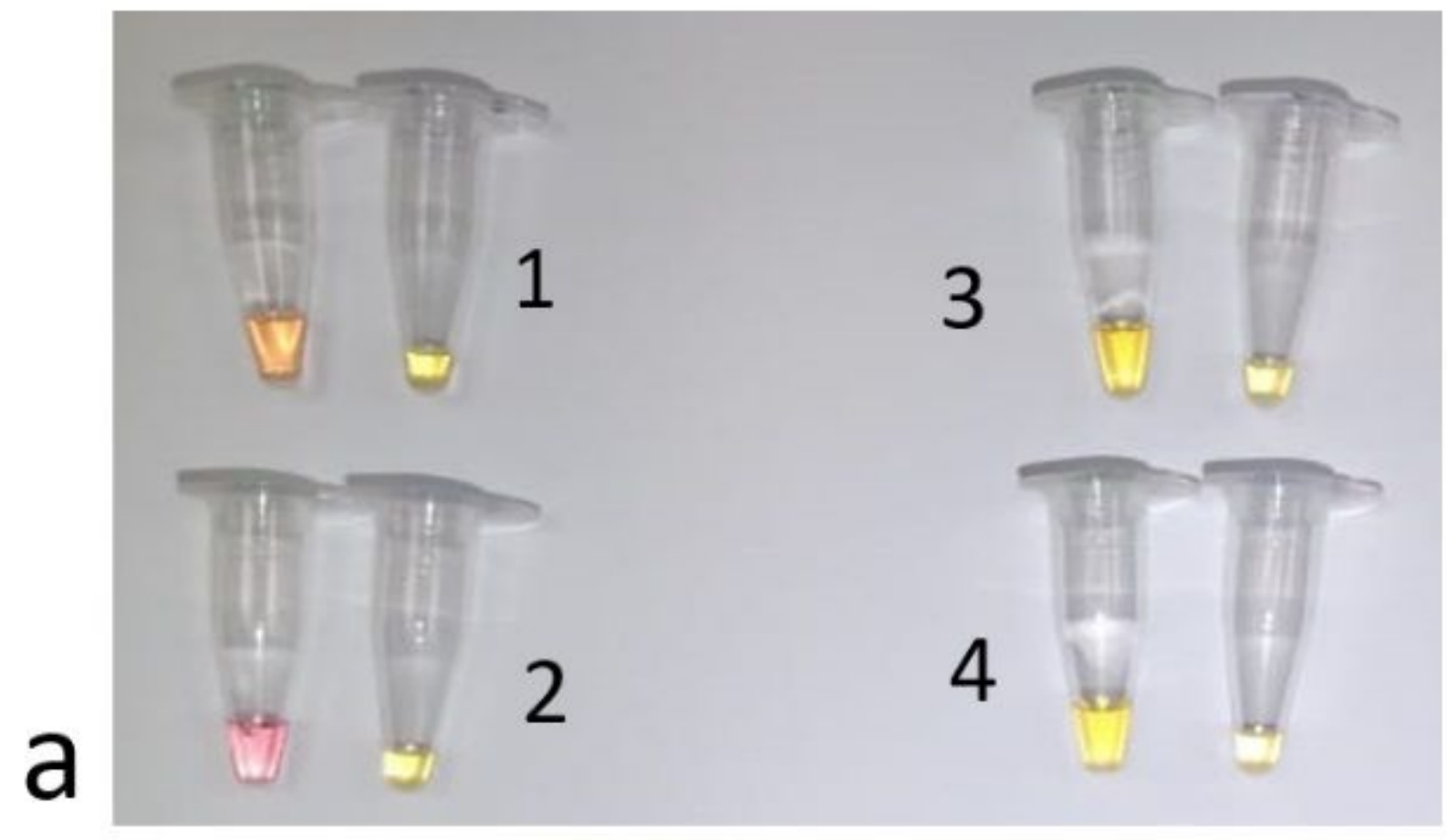

\section{Positive Negative}

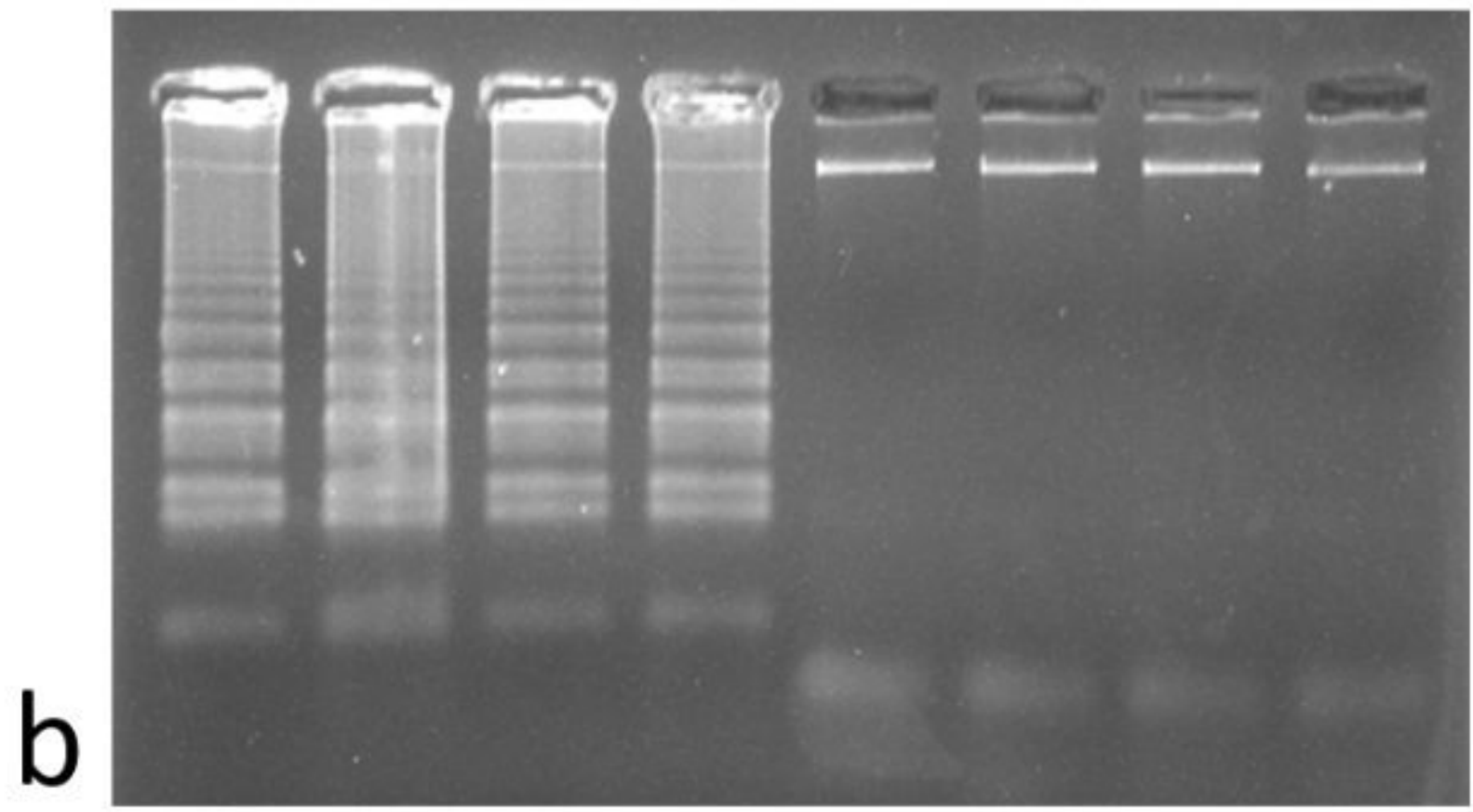

Figure 7

a. Colorimetric RT-LAMP for $4 \mathrm{CML}$ clinical samples and internal control (left and right, respectively), resulting in intermediate (sample 1), negative (sample 2) and positive (samples 3 and 4) for BCR-ABL p210 translocation detection; b. representative agarose gel electrophoresis with ethidium bromide staining for 4 positive and 4 negative colorimetric RT-LAMP 


\section{Supplementary Files}

This is a list of supplementary files associated with this preprint. Click to download.

- Supptable1.pdf 